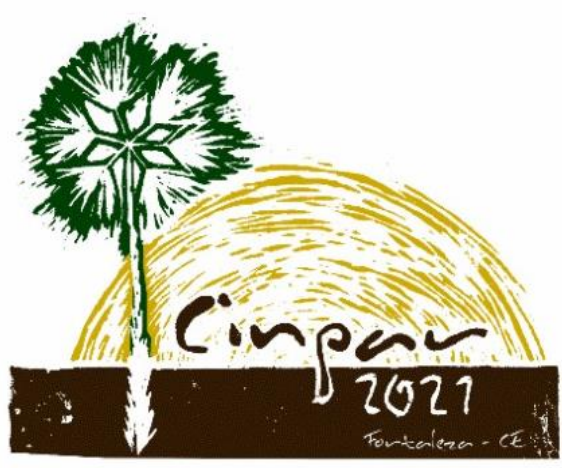

XVII Congresso Internacional sobre Patologia e

Reabilitação das Construções

XVII Congreso Internacional sobre Patología y Rehabilitación de las Construcciones

XVII International Conference on Pathology and Constructions Rehabilitation

FORTALEZA (Brasil), 3 a 5 de junho de 2021

https://doi.org/10.4322/CINPAR.2021.139

\title{
Manifestações Patológicas: Estudo de caso em um prédio público localizado em Balneário Camboriú/SC.
}

\section{Pathological Manifestations: Case study in a public building located in Balneário Camboriú / SC.}

\author{
Gabrieli GUCKERT ${ }^{1}$, Adrieli Nunes SCHONS ${ }^{2}$ \\ ${ }^{1}$ Faculdade Estácio de Florianópolis, Florianópolis, Brasil, gg.guckertgabrieli@gmail.com \\ ${ }^{2}$ Centro Universitário Estácio de Sá Santa Catarina, São José, Brasil, adrielischons@gmail.com
}

\begin{abstract}
Resumo: Patologia em construção é um ramo da engenharia civil que estuda os agentes que degradam a estrutura. A incidência de patologias está relacionada a falhas construtivas, falhas de projeto e a falta de manutenção. Além de deixar o ambiente esteticamente desagradável, as patologias podem interferir de forma grave na durabilidade e estabilidade da edificação. Identificar sua causa torna-se de extrema importância devido ao elevado custo para se realizar manutenções e retrabalhos. Nesse sentido, foi realizada uma análise das medidas tomadas in loco para sanar problemas patológicos encontrados em um prédio público localizado em Balneário Camboriú/SC. A metodologia adotada constitui-se de um estudo de caso acerca das patologias encontradas no prédio público supracitado. Com base na revisão bibliográfica, foram estudadas as prováveis causas das manifestações patológicas e apresentadas as medidas técnicas corretas para sanar cada patologia. A área da edificação que sofreu intervenções corresponde a 5,71\% da área total da construção. Por questões burocráticas e financeiras, grande parte das medidas tomadas foram paliativas, ou seja, com o passar do tempo essas patologias voltarão a ocorrer. Com base no estudo realizado, concluise que a prevenção é sempre a melhor alternativa, apesar de toda e qualquer estrutura estar sujeita a agentes causadores de avarias, quanto melhor planejada a execução e melhor o diagnóstico dos agentes causadores menores serão os custos com manutenções e retrabalhos, pois as soluções adotadas serão as mais eficazes.
\end{abstract}

Palavras-chave: Patologia. Manifestações Patológicas. Fissuras. Recalque Diferencial. Bolhas em tintas.

\begin{abstract}
Construction pathology is a civil engineering subject, which studies the agents that degrade structures. The incidence of pathologies is related to constructive flaws, project flaws and lack of maintenance. Besides leaving the building aesthetically unsightly, pathologies can seriously interfere in the construction's durability and stability. Identifying the pathologies' causes become extremely important due to the high cost of maintenance and rework. An analysis was made, about the measures in loco to solve the pathological problems in a public building located in Balneário Camboriú/SC. The adopted methodology consists of a case study about the pathologies found in the aforementioned building. Based on the bibliographic review, the probable causes of the pathological manifestations were studied and the correct technical measures to solve each of them were presented. The area of the building that underwent interventions corresponds to $5.71 \%$ of the total construction area. For bureaucratic and financial reasons most of the measures taken were palliative, meaning that in a short time these pathologies will happen again. Based on the study done, the conclusion is that prevention is always the best alternative. Although every structure is subjected to damage-causing agents, a well-planned construction and a correct diagnostic of the
\end{abstract}


pathologies' agents will result in less costs with maintenance and rework because the adopted solutions will be the most effective.

Keywords: Pathology. Pathological Manifestations. Fissure. Differential settlement. Bubbles in Paints.

\section{Introdução}

Patologia em construções é uma área do conhecimento cujo objetivo é permitir que o engenheiro compreenda os agentes causadores de falhas, defeitos e mecanismos que alteram visualmente o aspecto estrutural das edificações. Essa é uma área de extrema importância para aumentar a qualidade e durabilidade das edificações, de forma que busca eliminar as manifestações que degradam as estruturas (NAZARIO e ZACAN, 2011).

Além de deixar o ambiente esteticamente desagradável, as patologias podem interferir de forma grave no uso da edificação. A incidência de patologias está relacionada a falhas construtivas, falhas de projeto e a falta de manutenção. $O$ ideal é que durante a fase de projeto, os possíveis problemas sejam pensados e estudados, de forma que durante a construção da edificação essas eventualidades estejam previstas e o aparecimento de patologias relacionadas a elas sejam evitadas.

Todavia, quando a edificação está pronta e apresenta manifestações patológicas, é necessário realizar um estudo da situação, de forma a verificar se os problemas encontrados apresentam riscos estruturais a durabilidade da edificação. Esse estudo é de extrema importância para encontrar a causa raiz do problema, pois somente com um correto diagnóstico, medidas mais eficazes e definitivas poderão ser tomadas, eliminando assim gastos desnecessários com retrabalhos.

Nesse sentido, este trabalho visa fazer uma análise das medidas tomadas in loco para sanar problemas patológicos em um prédio público localizado em Balneário Camboriú/SC. Para tanto, foi realizado um estudo das patologias comumente encontradas em edificações, suas causas e medidas de correção, de forma a fazer a longo prazo uma análise técnica e financeira acerca da eficácia das medidas adotadas.

\section{Patologia em Construções}

Várias são as manifestações patológicas que podem ocorrer em edificações, estas manifestações podem ocorrer nas estruturas de concreto armado, bem como, nos demais componentes da construção. Muitas patologias coexistem e acabam sendo causadas por um agente degradador já presente na estrutura. Dentre as sintomatologias mais comuns estão: fissuras, deslocamentos, manchas, umidades, bolor e eflorescências (BORGES, 2008).

\subsection{Patologia em alvenaria}

As principais patologias encontradas em alvenarias nem sempre são causadas por um único agente degradador, o dificulta distinguir a causa da lesão. Nesse sentido, as fissuras também podem ser provocadas por adaptação ou acomodação da estrutura, recalques, compressão ou esmagamento, rotação e escorregamento (AZEREDO, 2018).

\subsubsection{Fissuras causadas por variações térmicas}

Diariamente os componentes da edificação estão sujeitos a variação diárias e sazonais de temperatura. Essas variações estão relacionadas a diversos fatores, como propriedades do material, intensidade da variação de temperatura e restrições impostas pelos vínculos de apoio do material. Os movimentos de contração e dilatação causados pelas variações térmicas, ao serem restringidas pelos apoios, causam tensões que tendem a resultar no aparecimento de fissuras Como o concreto e a alvenaria tem coeficiente de dilatação térmica diferente, ocorrem variações térmicas diferenciais entre esses componentes. A dilatação em lajes e elementos de concreto armado fazem com que apareçam tensões de tração e cisalhamento nas paredes,

Manifestações Patológicas: Estudo de caso em um prédio público localizado em Balneário Camboriú/SC. 
acarretando o aparecimento de trincas. A trinca característica dessa movimentação térmica entre parede e laje é paralela ao comprimento da última (THOMAZ, 1989).

\subsubsection{Fissuras causadas por sobrecargas}

As fissuras causadas por sobrecargas são oriundas de carregamentos verticais excessivos que tendem a comprimir os elementos estruturais e as paredes de alvenaria. As fissuras induzidas por esse excesso de carregamento podem ser verticais e horizontais, além de ocorrerem em paredes de alvenaria, podem aparecer em aparelhos de apoio, pilares e ao redor de aberturas de portas e janelas (MAGALHÃES, 2004).

\subsubsection{Fissuras causadas por recalques em fundações}

As fissuras causadas por recalque diferenciados são inclinadas e tendem a "deitar" em direção ao ponto em que sofreu maior recalque. Essa categoria de fissura apresenta forma de escamas, o que dá indícios das tensões de cisalhamento que acabaram provocando a abertura. Quando acentuados, os recalques tendem a provocar variações de abertura no decorrer da fissura (THOMAZ, 1989).

\subsection{Patologia em Pintura}

A tinta é uma película resistente que tem a função de proteger superfícies de agentes deterioradores e evitar a corrosão. Além da função de cobrimento, a sua função estética proporciona a valorização da estrutura. 0 pigmento (partículas em suspensão) tem a função é cobrir e decorar, enquanto o veículo, aglutina as partículas para formar a película de proteção (filme). O veículo é o constituinte mais importante da tinta, pois é através da sua modificação que surgiram tintas com diversas finalidades (BAUER, 1994)

\subsubsection{Bolhas}

Bolhas estão entre as doenças que podem aparecer em tintas. Seu aparecimento está geralmente relacionado à perda de adesão da tinta com a superfície, o que a longo prazo acarreta o levantamento do filme. A tinta pode perder adesão por diversos fatores, sendo o mais comum a umidade (POLITO, 2006). Dentre os fatores que contribuem para o aparecimento de umidade, o mais comum é por meio da condensação de água que infiltra por aberturas, como fissuras e trincas (BORGES, 2008).

\subsection{Testemunho de gesso}

As fissuras podem ser classificadas quanto a movimentação e tamanho da abertura. Com relação à movimentação, as fissuras podem ser chamadas ativas ou passivas (ASSIS e RABELO, 2013). Quanto a classificação em relação à abertura temos: fissuras, trincas e rachaduras. Segundo a NBR 9575/2003 aberturas de tamanho igual ou inferior a $0,5 \mathrm{~mm}$ são classificadas como fissuras, enquanto aberturas maiores que chegam até $1 \mathrm{~mm}$ são chamadas de trincas. Aberturas superiores a $1 \mathrm{~mm}$ podem ser classificadas como rachaduras. Já a NBR 15575/2013 nos traz uma classificação um pouco diferente. As trincas são classificadas como fissuras com abertura maior ou igual a $6,0 \mathrm{~mm}$.

Com a finalidade de se obter informações necessárias sobre o estado de uma construção, existem técnicas como inspeção visual, ensaio in situ e ensaios laboratoriais a partir de amostras retiradas in loco. A inspeção visual é um primeiro diagnóstico baseado principalmente na experiência, intuição e observação do profissional. Dentro do ensaio in situ tem-se uma técnica de monitoramento de fissuras chamadas de testemunhos. Os testemunhos permitem identificar o aumento nas aberturas (FERREIRA, 2010).

\section{Metodologia}

A metodologia utilizada para a elaboração deste artigo consistiu-se em uma revisão bibliográfica sobre o tema. Essa revisão bibliográfica foi procedida por um estudo de caso, cujo objetivo foi explorar os problemas patológicos encontrados no edifício público localizado no município de Balneário Camboriú/SC na forma de uma abordagem mais qualitativa. Ao final deste trabalho, é apresentada uma análise técnica e financeira das soluções paliativa e das soluções definitivas adotadas in loco, com o objetivo de avaliar a eficácia de cada uma delas a longo prazo.

Manifestações Patológicas: Estudo de caso em um prédio público localizado em Balneário Camboriú/SC. 


\section{Estudo de caso}

O prédio público objetivo deste trabalho tem função basicamente administrativa, está situado na região de Balneário Camboriú/SC e tem cerca de 55 anos. Durante o período de dezembro a janeiro, a construtora detentora do contrato de manutenção realizou serviços de cunho corretivo, preventivo e serviços de melhorias internas na edificação. Para isso, o órgão público emitiu uma Ordem de Serviço. Dentre os serviços executados, destacam-se as manutenções realizadas devido a: patologia em alvenaria; patologia em fundações e patologia em revestimento (tintas). O pavimento que sofreu intervenções foi o térreo.

Com o objetivo de melhor compreender o comportamento da edificação e estudar medidas mais definitivas para sanar os problemas encontrados, na oportunidade do estudo de caso entramos em contato com o setor de Engenharia responsável pela edificação buscando informações sobre as características estruturais da edificação e topografia do solo. Contudo, não recebemos um retorno favorável. Na época informaram que essas informações não estavam disponíveis. Nesse sentido, as medidas adotadas foram basicamente paliativas, com base no que conseguimos observar in loco e em pesquisas realizadas online.

Dessa pesquisa online obtivemos a informação de que o solo na região de Balneário Camboriú é do tipo areno-argiloso e a litologia encontrada é do tipo granítica (CEPED, UFSC, 2015). Com base na inspeção visual in loco, identificamos que em frente a edificação existe uma via movimentada com trânsito intenso de veículos leves e pesados. Essas duas informações, ajudaram a ter uma melhor compreensão do comportamento do solo e de sua relação com as patologias causadas pelo adensamento do mesmo.

\subsection{Fissuras, trincas e rachaduras}

A patologia encontrada em maior proporção foi a caracterizada por aberturas. As fissuras e trincas foram causadas basicamente por tensões oriundas de sobrecargas e variações térmicas diferenciais nas vigas e lajes que servem de apoio para a estrutura de vedação. Segundo informações pré-existentes, todos os prédios com a mesma arquitetura sofrem com esse problema.

Já as rachaduras foram provenientes de recalque diferencial devido ao adensamento do solo. $O$ adensamento de solo, bem como, o recalque em fundações são até certo ponto normais, pois toda fundação recalca e esse deslocamento é considerado no dimensionamento estrutural. Conforme pode ser observado na Figura 1, grande parte das aberturas encontradas na edificação tem a inclinação característica de recalque diferencial, que é de aproximadamente $45^{\circ}$.

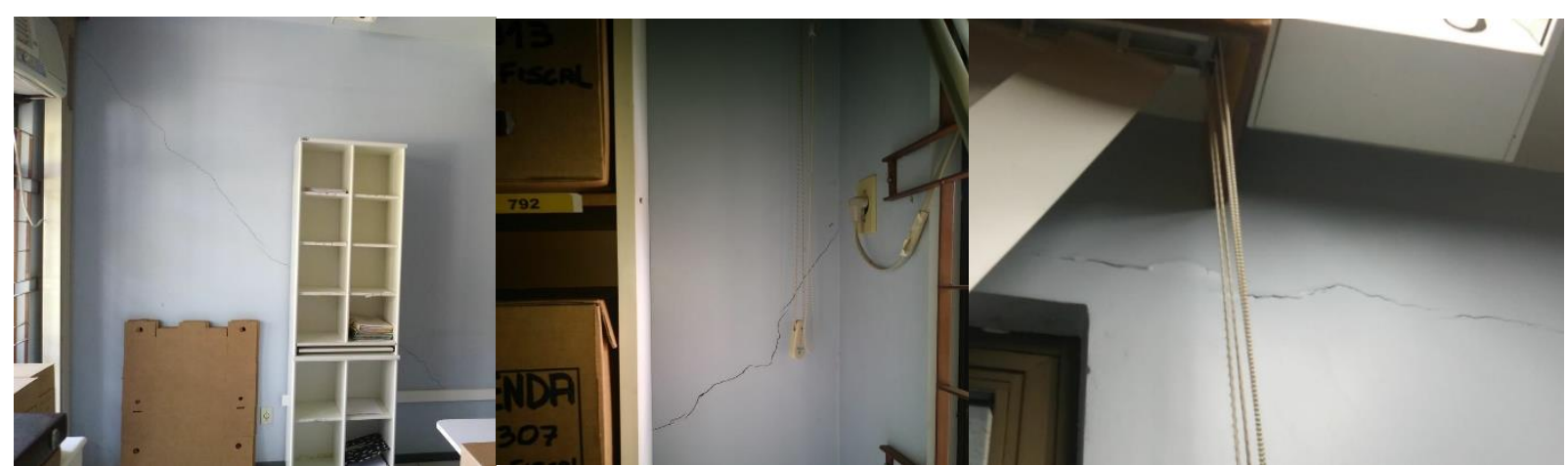

Figura 1 - Fissuras causadas por recalques na fundação, Trincas de cisalhamento provocada por sobrecarga e Fissuras causadas por provocada por movimentação térmica na estrutura

Fonte: Arquivo pessoal (2019)

A maior abertura encontrada apresentava $3 \mathrm{~mm}$, sendo considerada uma trinca. O procedimento realizado pode ser observado na Figura 2 e consistiu em: abertura e limpeza da cavidade (por meio da utilização de uma espátula), aplicação de uma demão de fundo preparador (tipo fixador de partículas, marca Suvinil) na abertura e nas faixas laterais, nivelamento da parede através de aplicação de camadas de massa corrida em PVA, lixação da superfície, aplicação de selador acrílico e pintura acrílica interna.

Manifestações Patológicas: Estudo de caso em um prédio público localizado em Balneário Camboriú/SC. 
O memorial descritivo do contrato de manutenção prevê que fissuras, trincas e rachaduras recebam tratamentos diferenciados. No entanto, todas as aberturas foram tratadas da mesma forma, isto é, como fissuras. A longo prazo, um incorreto tratamento ou um tratamento paliativo dessa patologia pode acarretar o reaparecimento dessas aberturas.

Partindo do pressuposto de que uma construção mal executada tende a apresentar mais problemas do que o normal e que o prédio já apresenta uma certa vida útil, encontrar uma alternativa definitiva se torna financeiramente complicado. Considerando que o prédio em questão é um prédio público, alguns pontos precisam ser destacados:

- Tudo o que é realizado de serviço em um prédio público precisa passar por mais de um setor e ser aprovado por mais de uma pessoa para que os serviços possam ser autorizados e posteriormente realizados.

- Quando esse serviço apresenta um vulto financeiro muito grande, essas burocracias se tornam ainda maiores.

- Uma reforma tão grande não poderia ser realizada por um contrato de manutenção, seria necessário a abertura de um processo licitatório para tratar especificamente dessa demanda, o que poderia levar anos.

- Dependendo do tempo que o prédio demoraria para ser reformado, é provável que uma nova edificação seja construída, de forma a transferir os serviços para essa nova edificação.

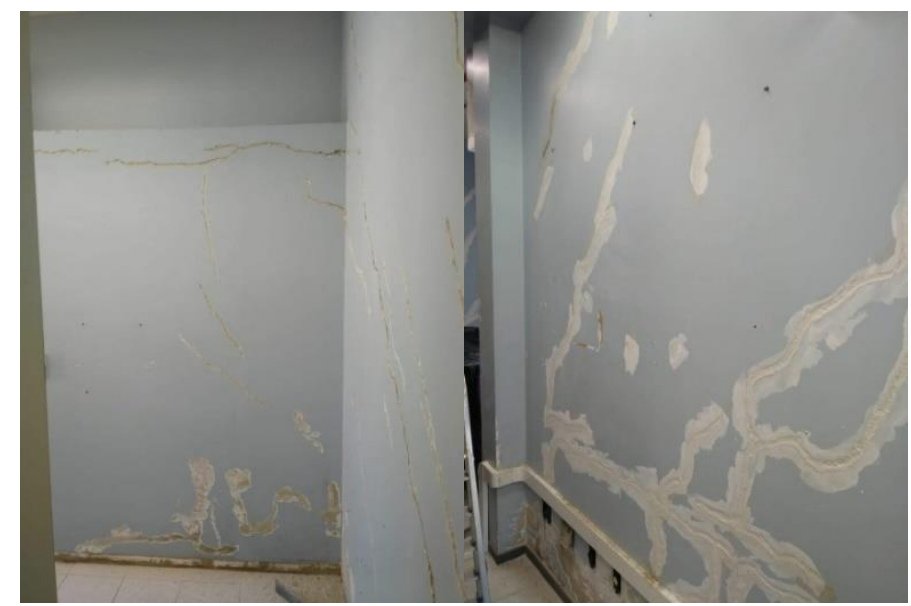

Figura 2 - Tratamento das aberturas: abertura e limpeza da cavidade e nivelamento da parede com massa corrida Fonte: Arquivo pessoal (2019)

\subsection{Bolhas nas paredes e tetos}

Na maior parte dos casos, as bolhas são causadas por problemas de infiltração. Com o tempo, a infiltração tende a provocar a perca de aderência entre a parede e o filme, resultando em bolhas. Os problemas de infiltração encontrados no térreo, se dividiam em duas causas principais: infiltração na laje dos banheiros e nos nichos dos aparelhos condicionadores de ar (Figura 3) e infiltrações advindas das paredes externas (Figura 4).

As infiltrações nos janeleiros foram causadas por conta dos drenos corroídos, a água que deveria escoar para a rua, estava escorrendo em cima da laje que serve de apoio para os condicionadores de ar, de forma que com o tempo apareceram infiltrações nos tetos dos banheiros. Como os janeleiros estão sendo trocados gradualmente, foi adotada uma medida paliativa.

Essa medida paliativa consistiu na demolição do contrapiso existente e execução de novo contrapiso com caimento na laje, de forma que a água não ficasse mais empoçada, além da execução de uma impermeabilização com borracha líquida. A medida definitiva já está sendo executada, porém, com as soluções paliativas adotadas, os problemas de infiltração não voltarão a ocorrer até que todos os janeleiros sejam substituídos.

Manifestações Patológicas: Estudo de caso em um prédio público localizado em Balneário Camboriú/SC. 
As infiltrações nas paredes por conta de umidade externa são de mais difícil diagnóstico e correção quando comparadas as infiltrações pelos drenos dos janeleiros. Provavelmente, na época em que o prédio foi construído não foi realizada uma correta impermeabilização entre a infraestrutura e superestrutura, corrigir um problema desse nessa fase da vida útil da edificação é muito mais complicado e oneroso, além de que as oportunidades de se obter sucesso são controversas.

Visando corrigir os problemas de bolhas, primeiro foi verificado a integridade do reboco. Onde o reboco estava integro, a parede foi lixada e repintada, sem mais cuidados. Nas paredes onde o reboco não estava integro, o mesmo foi demolido e refeito sem considerar alguma forma de impermeabilização. O problema das bolhas foi tratado, mas como a causa da infiltração não foi diagnosticada e resolvida, com o decorrer do tempo as bolhas voltarão a aparecer. Diferente da situação da infiltração dos drenos, cuja medida definitiva já está sendo tomada, a infiltração pela umidade não tem uma solução definitiva em vista. Por fim, todas as paredes foram raspadas e lixadas.

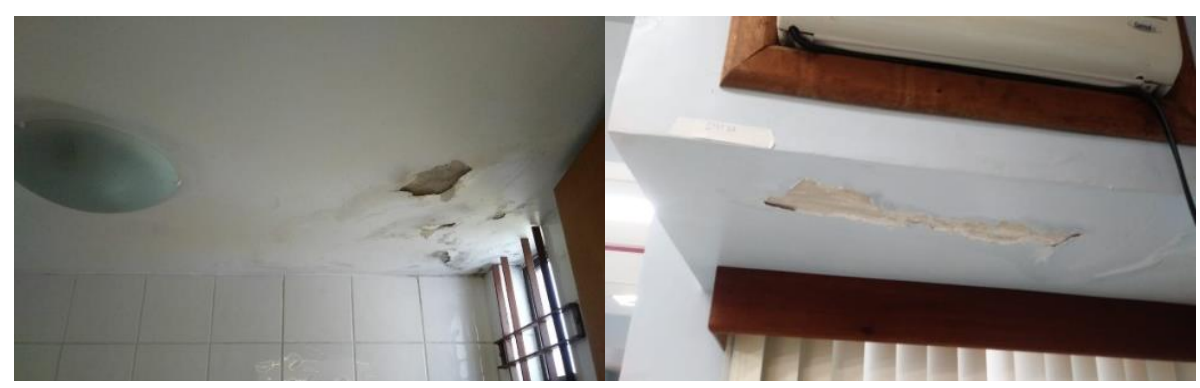

Figura 3 - Bolhas no teto e nichos do aparelho janeleiro Fonte: Arquivo pessoal (2019).

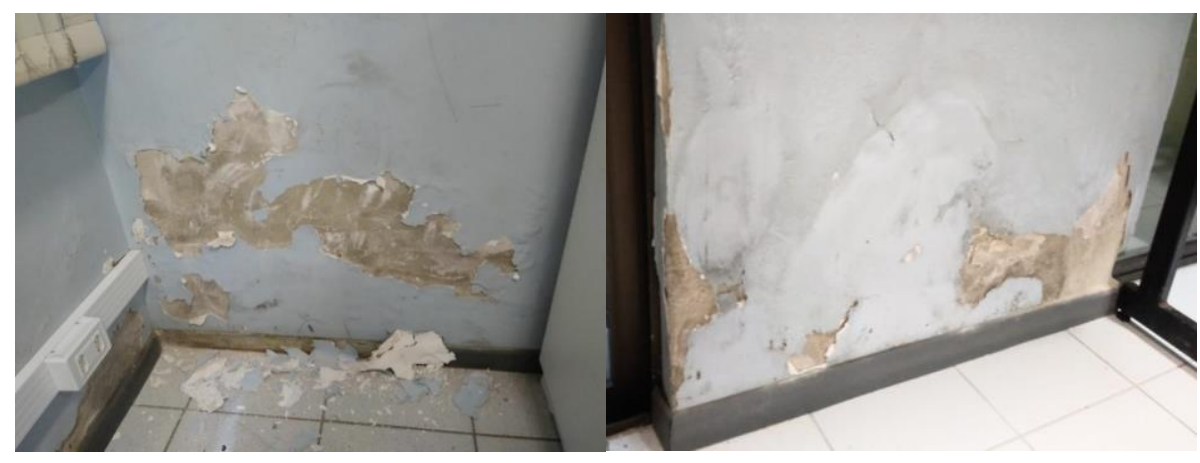

Figura 4 - Bolhas nas paredes

Fonte: Arquivo pessoal (2019).

\subsection{Testemunho rígido de gesso}

Conforme citado anteriormente, o testemunho de gesso é uma técnica de monitorização para verificar a evolução de fissuras, trincas e rachaduras, de modo a saber se as mesmas ainda estão ativas ou se já estão estabilizadas. O local escolhido para realização do testemunho foi a garagem, local onde havia uma rachadura de $3 \mathrm{~mm}$. Os serviços consistiram basicamente na abertura da rachadura com uma espátula e na sua limpeza com um pincel. $O$ gesso utilizado para a execução do testemunho é do tipo em pó, após a abertura e limpeza da cavidade, o gesso foi diluído em água e aplicado com uma espátula na abertura de forma a preenchê-la (Figura 5).

Apesar de haver núcleos melhores e mais sensíveis disponíveis no mercado para a execução de testemunhos e verificação de deformações, quando comparados ao gesso, a escolha da utilização desse material justificasse na existência de item similar ao referido serviço no contrato de manutenção da edificação.

O testemunho foi feito em 30/04/2020 para verificar a incidência de novas aberturas e sua evolução foi monitorada até final de setembro. Durante esse período, tivemos a migração do inverno para a primavera

Manifestações Patológicas: Estudo de caso em um prédio público localizado em Balneário Camboriú/SC. 
de forma que a estrutura da edificação começou a sofrer variações significativas de temperatura, favorecendo retrações térmicas nos elementos de concreto armado. Após decorrido o tempo de espera, não foram verificadas aberturas relevantes no testemunho, levando-nos a conclusão de que o solo de assentou e que as fissuras, trincas e rachaduras causadas pelos recalques diferenciais não ocorrerão mais. Entretanto, foi verificado pequenas fissuras relacionadas a variação de temperatura.

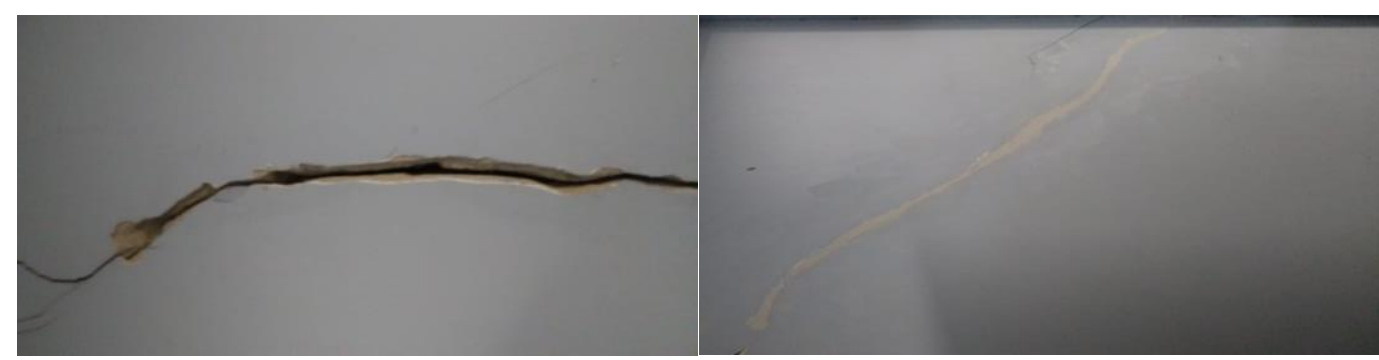

Figura 5 - Abertura e limpeza da cavidade com uma espátula (à esquerda). Preenchimento da fissura com gesso (à direita).

Fonte: Arquivo pessoal (2020)

\section{Conclusões}

O prédio estudado é composto por 4 pavimentos, incluindo o térreo. A área dos 4 pavimentos é estimada em $7.550 \mathrm{~m}^{2}$ e a área de que sofreu intervenção é de aproximadamente $431 \mathrm{~m}^{2}$, correspondendo a cerca de $5,71 \%$ da edificação. Apesar da alternativa correta e econômica ser adotar soluções definitivas, não foram realizados estudos aprofundados visando diagnosticar a causa raiz das patologias.

A técnica de diagnóstico adotada consistiu basicamente em inspeção visual das avarias encontradas in loco. A inspeção visual considerou a experiência, intuição e observações do profissional de engenharia. Após concluso os serviços, foi realizada uma técnica de diagnóstico complementar a inspeção visual, denominada testemunho de gesso.

Esse testemunho teve como objetivo verificar se as fissuras, principalmente as causadas por recalque diferencial, ainda estão ativas ou se já estão estabilizadas. No entanto, essa medida está sendo tomada de forma tardia, pois todas as salas já foram repintadas e para um melhor diagnóstico e correta análise dos dados, esse testemunho deveria ter sido realizado inclusive nessas salas.

O problema patológico de bolhas nas lajes dos banheiros, causado por infiltração oriunda dos drenos corroídos dos aparelhos janeleiros, tem como medida definitiva a substituição desses aparelhos por condicionadores splits. Como essa substituição está sendo realizada de maneira gradativa devido ao grande vulto financeiro envolvido nesse serviço, a execução de um contrapiso com inclinação e posterior impermeabilização das lajes com borracha líquida, torna-se uma medida corretiva eficaz. Até que todos os aparelhos sejam trocados, a água dos drenos não causará mais infiltração nessas lajes.

Em contrapartida, os problemas de infiltrações externas não foram estudados por questões burocráticas, logo a causa raiz dessa umidade não foi diagnosticada e os serviços foram somente paliativos. Onde o reboco não estava íntegro, ele foi refeito sem considerar alguma impermeabilização. No final as paredes com essa manifestação patológica foram raspadas e repintadas.

Grande parte dos problemas que uma estrutura apresenta no futuro são oriundos principalmente de mau planejamento, projeto ineficiente ou falhas construtivas. Para identificar com certeza a origem dos problemas, precisaríamos primeiramente de informações que não temos acesso, como, por exemplo, conhecimento acerca do processo construtivo. Nesse sentido, a falta de informações torna o diagnóstico das patologias e a manutenção da edificação algo complexo e oneroso.

Por se tratar de um prédio público o fator tempo e burocracia devem ser considerados. O contrato de manutenção contempla serviços pontuais e com baixo vulto financeiro. Os serviços para correção das

Manifestações Patológicas: Estudo de caso em um prédio público localizado em Balneário Camboriú/SC. 
patologias foram, em grande parte, medidas paliativas e ainda assim apresentaram uma importância financeira de cerca de $\mathrm{R} \$ 50.000,00$.

Fazendo uma projeção de forma a considerar a execução dos mesmos serviços nas demais salas da edificação, ou seja, nos outros 4 pavimentos, a importância financeira é estimada em aproximadamente $\mathrm{R} \$ 900.000,00$. Obviamente, esse valor será bem maior se for executada uma reforma na totalidade da edificação, pois cada sala apresenta sua particularidade.

Com base nas informações prestadas acima, mesmo que as causas raízes de todos os problemas patológicos fossem identificados pela contratada, é financeiramente inviável corrigi-los por meio do contrato de manutenção, devido principalmente ao grande vulto financeiro envolvido nessa demanda.

Com base nas informações prestadas, conclui-se que a prevenção é sempre a melhor alternativa, que apesar de toda estrutura estar sujeita ao aparecimento de patologias, quanto melhor planejada a execução e melhor for o diagnóstico dos agentes causadores de avarias, mais eficazes serão as medidas tomadas, maior será a durabilidade e a vida útil da edificação e menor será o custo com manutenções e retrabalhos.

\section{Referências Bibliográficas}

ABNT. NBR 9575 - Impermeabilização - Seleção e projeto. 4‥ ed. Rio de Janeiro: ASSOCIAÇÃO BRASILEIRA DE NORMAS TÉCNICAS, 2003.

ABNT. NBR 15575 - Edificações habitacionais - Desempenho. Rio de Janeiro: ASSOCIAÇÃO BRASILEIRA DE NORMAS TÉCNICAS, 2013.

ASSIS, F. F. D.; RABELO, G. Q. Fissuras por Movimentação Térmica em Estruturas de Concreto Armado. Goiânia: Universidade Federal de Goiás, 2013. 2 p. (Monografia).

AZEREDO, H. A. D. O edifício e seu acabamento. 14‥ ed. São Paulo: Edgard Blucher Ltda., 2018.

BAUER, F. L. A. Materiais de construção. Rio de Janeiro: LTC - Livros Técnicos e Científicos Editora S.A., v. 2, 1994. 659 - 660 p.

BORGES, G. M. Manifestações patológicas incidentes em reservatórios de água elevados executados em concreto armado. Feira de Santana: Universidade Estadual de Feira de Santana, 2008. 7-8 p. Monografia (Graduação).

CEPED, UFSC. Análise de vulnerabilidade a desastre do Município de Balneário Camboriú. Florianópolis: CEPED UFSC, 2015. 35, 72, 93 p.

FERREIRA, J. A. D. A. Técnicas de Diagnóstico de Patologias em Edifícios. Porto: Faculdade de Engenharia da Universidade do Porto, 2010. 37 - 51 p. (Dissertação).

MAGALHÃES, E. F. D. Fissuras em alvenarias: configurações típicas e levantamento de incidências no Estado do Rio Grande do Sul. Porto Alegre: Universidade Federal do Rio Grande do Sul, 2004. 41 - p. (Dissertação).

NAZARIO, D.; ZACAN, E. C. Manifestações das patologias construtivas nas edificações públicas da rede municipal de Criciúma: inspeção dos sete postos de saúde. Criciúma: Universidade do extremo Sul Catarinense (UNESC)., 2011. 2 p. Artigo (Graduação).

POLITO, G. Principais Sistemas de Pintura e suas Patologias. Minas Gerais: Universidade Federal de Minas Gerais (UFMG), 2006. 35 p. (Apostila).

THOMAZ, E. Trincas em edifícios: causas, prevenção, e recuperação. ( 3. tiragem 1998). ed. São Paulo: PINI: Instituto de Pesquisas Tecnológicas, 1989. 19-25, 45,83, 94-102,159 p.

Manifestações Patológicas: Estudo de caso em um prédio público localizado em Balneário Camboriú/SC. 